\title{
Prediction of Explosion Heat of Aluminized Explosive Based on Artificial Neural Network
}

\author{
Xin Tian, Yonggang Liu and Yueqiang Jiang \\ Institute of Chemical Materials, CAEP, China
}

\begin{abstract}
In this study, a three-layer artificial neural network(ANN) model was constructed to predict the explosion heat (Q) of aluminized explosive. Elemental composition was employed as input descriptors and explosion heat was used as output. The dataset of 24 aluminized explosives was randomly divided into a training set (17) and a prediction set (7). After optimized by adjusting various parameters, the optimal condition of the neural network was obtained. Simulated with the final optimum neural network, calculated explosion heat shows good agreement with experimental values. It is shown here ANN is able to produce accurate predictions of the explosion heat of aluminized explosive.
\end{abstract}

Keywords-aluminized explosive; explosion heat; artificial neural network

\section{INTRODUCTION}

Since aluminized explosive has the characteristics of high explosion heat and temperature and post-detonation burning effect, it is widely used in rocket propellants, underwater munitions, air armaments, mine blasting, geological survey and even lunar development.

Explosion heat (Q) is one of the most important detonation parameters for aluminized explosive. To predict the explosion heat accurately is significant to the study of new aluminized explosive. There are usually two methods to calculate Q: (1) It can be obtained using Hess Law based on the detonation products. In this method, the detonation products are usually defined based on experience, which is difficult for a novice. And also the formation heat of reactants and products should be used, which must be calculated or measured beforehand. (2) It also can be calculated using eigenvalue of explosion heat of the components, which is demarcated by experiments. Based on the mass percentages of the components, explosion heat of aluminized explosive is obtained using additive method. However this method can not be used for the components of which eigenvalue of explosion heat has not been demarcated. So it is necessary to find a simple and comprehensive prediction method of explosion heat.

Recently, the ANN modeling technique has been used successfully in prediction of impact sensitivity [1-3] and detonation parameters of pure explosives [4]. In this paper, the ANN was employed to investigate the relationship between explosion heat and elemental composition of aluminized explosive (CaHbNcOdAle). The main goal of this study is to set up an ANN model of prediction of explosion heat.

\section{ANALYSIS OF THE INPUT DESCRIPTORS}

What is known as a critical aspect to construct an ANN model is the selection of suitable input descriptors. The descriptors should reflect the influencing factors of explosion heat as much as possible.

In simple terms, explosion heat, namely, constant volume combustion heat, refers to the heat released in combustion process of explosive or propellant. In this process, a redox reaction occurs between the combustion elements $(\mathrm{C}, \mathrm{H}, \mathrm{N}, \mathrm{Al})$ and the oxidation element (O). Simultaneously, it releases heat. Therefore, it is reasonable to represent explosion heat as a function of the elemental composition $(\mathrm{a}, \mathrm{b}, \mathrm{c}, \mathrm{d}, \mathrm{e})$ of the aluminized explosive. That is to say, elemental composition should be selected as the input descriptor.

A close examination of experimental results shows that explosion heat has a a close correlation with the loading density $(\rho)$. Hence, loading density is also a necessary input descriptor.

As discussed above, a,b,c,d,e and $\rho$ were selected as the input descriptors to construct an ANN model.

\section{ANN MODEL FOR EXPLOSION HEAT}

ANN modeling, which originated about 60 years ago, is a parallel processing technique inspired by the desire to emulate human learning activity [5]. It is a highly self-organized, selfadapted, and self-trainable approximator, with high associative memory and strong non-linear mapping ability as well. By simulating the human neural system from micro-mechanism, ANN model can simulate complex and non-linear problems by employing a different number of non-linear processing elements, i.e. the nodes or neurons $[6,7]$.

Usually, the network has one input layer, one hidden layer and one output layer. The input layer is consisted by the input descriptors. Information from the input layer is then processed in the course of the hidden layer, following output vector is computed in the output layer. In this study, the vector of input layer is $\mathrm{X}=(\mathrm{x} 1, \mathrm{x} 2, \ldots, \mathrm{x} 6)=(\mathrm{a}, \mathrm{b}, \mathrm{c}, \mathrm{d}, \mathrm{e}, \rho)$, and the output is $\mathrm{Y}=(\mathrm{y} 1)=(\mathrm{Q})$.

In developing an ANN model, the available dataset (Table 1) was randomly divided into two sets, a training set (17) and a prediction set (7). They were used for training of the network and verifying the generalization capability of the network, respectively. Various kinds of ANN approaches had been tried in this work. As a result, the linear ANN with Least Mean Square Error (LMSE) learning algorithm is the most accurate 
ANN model to predict explosion heat. A schematic description of the linear ANN is given in Fig. 1.

TABLE I. PARAMETERS USED AS INPUT DESCRIPTORS

\begin{tabular}{|c|c|c|c|c|c|c|}
\hline No. & $\mathbf{a}$ & $\mathbf{b}$ & $\mathbf{c}$ & $\mathbf{d}$ & $\mathbf{e}$ & $\begin{array}{c}\mathbf{Q} \\
{[\mathbf{k J} / \mathbf{k g}]}\end{array}$ \\
\hline 1 & 13.381 & 26.191 & 26.477 & 25.649 & 0 & 5770 \\
\hline 2 & 12.512 & 23.992 & 22.961 & 22.961 & 0 & 5490 \\
\hline 3 & 14.931 & 25.736 & 21.61 & 21.61 & 0 & 4690 \\
\hline 4 & 15.211 & 29.172 & 26.589 & 25.882 & 0 & 5066 \\
\hline 5 & 27.717 & 19.798 & 23.757 & 11.879 & 3.704 & 5307 \\
\hline 6 & 21.557 & 15.398 & 18.478 & 9.239 & 11.111 & 6519 \\
\hline 7 & 20.422 & 25.006 & 26.765 & 21.486 & 0 & 5020 \\
\hline 8 & 27.554 & 27.206 & 25.354 & 6.599 & 0 & 5150 \\
\hline 9 & 24.843 & 42.113 & 22.146 & 0 & 0 & 4850 \\
\hline 10 & 13.107 & 26.417 & 20.529 & 20.529 & 0 & 6443 \\
\hline 11 & 9.845 & 19.765 & 17.557 & 17.557 & 0 & 7046 \\
\hline 12 & 6.888 & 13.776 & 13.776 & 13.776 & 14.815 & 8368 \\
\hline 13 & 10.94 & 21.88 & 21.88 & 21.88 & 3.667 & 6357 \\
\hline 14 & 11.021 & 22.042 & 22.042 & 22.042 & 1.481 & 5586 \\
\hline 15 & 10.67 & 21.34 & 21.34 & 21.34 & 2.444 & 6006 \\
\hline 16 & 10.089 & 20.178 & 20.178 & 20.178 & 3.926 & 6236 \\
\hline 17 & 9.819 & 19.638 & 19.638 & 19.638 & 4.926 & 6415 \\
\hline 18 & 8.874 & 17.747 & 17.747 & 17.747 & 7 & 6704 \\
\hline 19 & 8.644 & 17.288 & 17.288 & 17.288 & 11.111 & 8317 \\
\hline 20 & 11.345 & 22.69 & 22.69 & 22.69 & 3.704 & 6366 \\
\hline 21 & 9.995 & 19.989 & 19.989 & 19.989 & 7.407 & 6760 \\
\hline 22 & 8.644 & 17.288 & 17.288 & 17.288 & 11.111 & 7709 \\
\hline 23 & 7.293 & 14.587 & 14.587 & 14.587 & 14.815 & 8299 \\
\hline 24 & 13.478 & 26.696 & 25.653 & 25.392 & 0 & 5663 \\
\hline
\end{tabular}

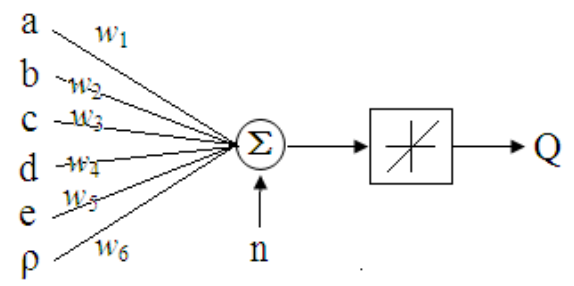

FIGURE I. THE STRUCTURE OF LINEAR ANN

\section{RESULTS AND DISCUSSION}

As discussed above, a 5-9-1 ANN model was set up for predicting explosion heat of aluminized explosive. The predicted results by ANN model, experimental data and the calculated values by empirical equation of eigenvalue of explosion heat (EE) [8] for 7 aluminized explosives are presented in Table 2.

As can been seen in Table 2, the ANN model shows good ability for explosion heat of aluminized explosives prediction. The maximum error of predicted values is $3.83 \%$. It is remarkable that the present ANN method is exceedingly simple, there is no need to use any experimental or calculated parameters. The input descriptors (a, b, c, d, e) can be easily obtained once the explosive formula confirmed.
TABLE II. COMPARISON OF P PREDICTED USING ANN MODEL AND MEASURED VALUES

\begin{tabular}{|c|c|c|c|c|c|}
\hline No & $\begin{array}{c}\boldsymbol{Q} \\
\text { (Exp.) } \\
{[\mathbf{k J} / \mathbf{k g}]}\end{array}$ & $\begin{array}{c}\boldsymbol{Q} \\
(\mathbf{A N N}) \\
{[\mathbf{k J} / \mathbf{k g}]}\end{array}$ & $\begin{array}{c}\text { Dev. } \\
(\mathbf{A N N}) \\
{[\%]}\end{array}$ & $\begin{array}{c}\boldsymbol{Q} \\
(\mathbf{E E}) \\
{[\mathbf{k J} / \mathbf{k g}]}\end{array}$ & $\begin{array}{c}\text { Dev. } \\
\text { (EE) } \\
{[\%]}\end{array}$ \\
\hline 1 & 5770 & 5549 & -3.83 & 5770 & -3.83 \\
\hline 2 & 5490 & 5645 & 2.83 & 5793 & 5.52 \\
\hline 7 & 5020 & 4981 & -0.78 & 5211 & 3.80 \\
\hline 11 & 7046 & 7040 & -0.08 & 7386 & 4.83 \\
\hline 13 & 6357 & 6321 & -0.56 & 6357 & 0.00 \\
\hline 23 & 8299 & 8479 & 2.17 & -- & -- \\
\hline 24 & 5663 & 5524 & -2.45 & -- & -- \\
\hline Note: -- Lack of necessary eigenvalue of explosion heat to calculate. \\
\hline
\end{tabular}

As can been seen in Table 2, the ANN model shows good ability for explosion heat of aluminized explosives prediction. The maximum error of predicted values is $3.83 \%$. It is remarkable that the present ANN method is exceedingly simple, there is no need to use any experimental or calculated parameters. The input descriptors ( $a, b, c, d, e)$ can be easily obtained once the explosive formula confirmed.

\section{CONCLUSION}

A well-trained ANN model was successfully used to predict explosion heat of aluminized explosives. Good agreement between the simulated values and the experimental values proved the utility of this method in a certain extent. The successful application also provided a simple and convenient way to predict other performances, such as detonation velocity and pressure, of composite explosives.

TABLE III. APPENDIX. EXPLOSIVE FORMULA

\begin{tabular}{|c|c|}
\hline No. & Formula \\
\hline 1 & $\mathrm{HMX} / 94 / \mathrm{NC} / 3 / \mathrm{Binder} / 3$ \\
\hline 2 & $\mathrm{HMX} / 95 / \mathrm{Binder} / 5$ \\
\hline 3 & $\mathrm{HMX} / 95 / \mathrm{Bin} / \mathrm{Binder} / 4.5$ \\
\hline 4 & $\mathrm{TNT} / 90 / \mathrm{Al} / 10$ \\
\hline 5 & $\mathrm{TNT} / 70 / \mathrm{Al} / 30$ \\
\hline 6 & $\mathrm{TNT} / 40 / \mathrm{RDX} / 60$ \\
\hline 7 & $\mathrm{PETN} / 80 / \mathrm{Binder} / 20$ \\
\hline 8 & $\mathrm{RDX} / 76 / \mathrm{W} / 4 / \mathrm{Al} / 20$ \\
\hline 9 & $\mathrm{RDX} / 65 / \mathrm{W} / 1.5 / \mathrm{G} / 1.5 / \mathrm{Al} / 32$ \\
\hline 10 & $\mathrm{HMX} / 51 / \mathrm{Al} / 40 / \mathrm{Binder} / 9$ \\
\hline 11 & $\mathrm{HMX} / 81 / \mathrm{Al} / 9.9 / \mathrm{Binder} / 9.1$ \\
\hline 12 & $\mathrm{HMX} / 81.6 / \mathrm{Al} / 4 / \mathrm{Binder} / 14.4$ \\
\hline 13 & $\mathrm{HMX} / 79 / \mathrm{Al} / 6.6 / \mathrm{Binder} / 14.4$ \\
\hline 14 & $\mathrm{HMX} / 74.7 / \mathrm{Al} / 10.6 / \mathrm{Binder} / 14.7$ \\
\hline 15 & $\mathrm{HMX} / 72.7 / \mathrm{Al} / 13.3 / \mathrm{Binder} / 14$ \\
\hline 16 & $\mathrm{HMX} / 65.7 / \mathrm{Al} / 18.9 / \mathrm{Binder} / 15.4$ \\
\hline 17 & $\mathrm{HMX} / 64 / \mathrm{Al} / 30 / \mathrm{Binder} / 6$ \\
\hline 18 & $\mathrm{HMX} / 84 / \mathrm{Al} / 10 / \mathrm{Binder} / 6$ \\
\hline 19 & $\mathrm{HMX} / 74 / \mathrm{Al} / 20 / \mathrm{Binder} / 6$ \\
\hline 20 & $\mathrm{HMX} / 64 / \mathrm{Al} / 30 / \mathrm{Binder} / 6$ \\
\hline 21 & $\mathrm{HMX} / 54 / \mathrm{Al} / 40 / \mathrm{Binder} / 6$ \\
\hline 22 & \\
\hline 23 & \\
\hline 24 & \\
\hline & \\
\hline & \\
\hline
\end{tabular}




\section{REFERENCES}

[1] H. Nefati, J.M. Cense, J.J. Legendre, Prediction of the impact sensitivity by neural networks, J. Chem. Inf. Sci. 36 (1996) 804-810.

[2] S.G. Cho, K.T. No, E.M. Goh, et al., Optimization of neural networks architecture for impact sensitivity of energetic molecular, Bull. Korean Chem. Soc. 26 (2005) 399-408

[3] M.H. Keshavarz, M. Jaafari, Investigation of the various structure parameters for predicting impact sensitivity of energetic molecules via artificial neural network, Propellants Explos. Pyrotech. 31 (2006) 216225.

[4] Ma Guichun, Zhang Shusheng, Zhang Jinglin, The progress of Artificial Neural Network Technique in explosives, Initiators \& Pyrotechnics. 01(2005) 42-44.

[5] Martin T, Howard B, Mark H, Neural network design, Thomson learning, 2002

[6] Wang ST, Fuzzy system, fuzzy neural network and application programming, Shanghai Scientific and Technical Literature Publishing Company, 1998.

[7] Xu LN. Neural network control, Beijing: Electronic Industry publishing company, 2003

[8] Sun Yebin, Military Composite Explosive, Weapon Industrial Press, 1994. 